Western University

Scholarship@Western

Aboriginal Policy Research Consortium International (APRCi)

$12-2006$

\title{
Claiming Space: Aboriginal Students within School Landscapes
}

Cathy Van Ingen

Joannie Halas

Follow this and additional works at: https://ir.lib.uwo.ca/aprci

Part of the Bilingual, Multilingual, and Multicultural Education Commons

Citation of this paper:

Van Ingen, Cathy and Halas, Joannie, "Claiming Space: Aboriginal Students within School Landscapes" (2006). Aboriginal Policy Research Consortium International (APRCi). 292.

https://ir.lib.uwo.ca/aprci/292 
This article was downloaded by: [University of Western Ontario]

On: 30 October 2012, At: 09:29

Publisher: Routledge

Informa Ltd Registered in England and Wales Registered Number: 1072954 Registered

office: Mortimer House, 37-41 Mortimer Street, London W1T 3J H, UK

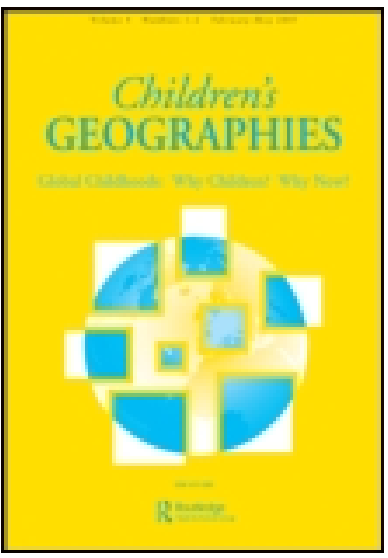

\title{
Children's Geographies
}

Publication details, including instructions for authors and subscription information:

http:// www.tandfonline.com/loi/ cchg20

\section{Claiming Space: Aboriginal Students within School Landscapes}

\author{
Cathy Van Ingen ${ }^{a} \&$ J oannie Halas ${ }^{b}$ \\ a Department of Physical Education \& Recreation, Brock \\ University, 500 Glenridge Ave., St. Catharines, Ontario, Canada, \\ L2S 3A1. Phone: +1 905688 5550, ext. 4981 \\ ${ }^{b}$ Faculty of Physical Education and Recreation Studies, University \\ of Manitoba, Canada \\ Version of record first published: 11 Dec 2006.
}

To cite this article: Cathy Van Ingen $\&$ J oannie Halas (2006): Claiming Space: Aboriginal Students within School Landscapes, Children's Geographies, 4:3, 379-398

To link to this article: http:// dx.doi.org/ 10.1080/ 14733280601005856

\section{PLEASE SCROLL DOWN FOR ARTICLE}

Full terms and conditions of use: http://www.tandfonline.com/page/terms-andconditions

This article may be used for research, teaching, and private study purposes. Any substantial or systematic reproduction, redistribution, reselling, loan, sub-licensing, systematic supply, or distribution in any form to anyone is expressly forbidden.

The publisher does not give any warranty express or implied or make any representation that the contents will be complete or accurate or up to date. The accuracy of any instructions, formulae, and drug doses should be independently verified with primary sources. The publisher shall not be liable for any loss, actions, claims, proceedings, demand, or costs or damages whatsoever or howsoever caused arising directly or indirectly in connection with or arising out of the use of this material. 


\title{
Claiming Space: Aboriginal Students within School Landscapes
}

\author{
CATHY VAN INGEN AND JOANNIE HALAS \\ Cathy van Ingen, Department of Physical Education \& Recreation, Brock University, 500 \\ Glenridge Ave., St. Catharines, Ontario, Canada L2S 3A1. Tel: + 1905688 5550, ext. \\ 4981. Fax: +1905688 8364. E-mail: cathy.vaningen@brocku.ca \\ Joannie Halas, Faculty of Physical Education and Recreation Studies, University of \\ Manitoba, Canada
}

\begin{abstract}
There is an emerging body of theoretical, historical and design research that examines the ways in which race and cultural identity are understood to be produced and represented in the landscape. Yet, there remains a dearth of research examining both the historic and contemporary effects of race upon the development of school geographies. This paper has two broad purposes. It highlights the experiential aspects of racialized geographies within schools and, at the same time, it grapples with the processes that maintain or challenge the spatial conditions for the construction of whiteness. Drawing upon in-depth case study research this paper highlights the experiences of Aboriginal students and staff at four different schools, with a particular focus on cross-cultural schools, in Manitoba, Canada.
\end{abstract}

KEYwords: School landscapes, racialized geographies, Aboriginal, contact zone, case study

What is needed is a concept of landscape that helps point the way to those interventions that can bring about much greater social justice. And what landscape study needs even more is a concept of landscape that will assist the development of the very idea of social justice. (Henderson, 2003, p. 196)

\section{Introduction}

\section{Schools as Contact Zones}

[Field notes: I am entering a public high school in rural Manitoba. As I walk up the stairs to the main entrance I stroll through a set of double doors painted in a dark solid color. In the foyer I am standing on a black carpet, there to collect the outside grime at the entrance before the hallway extends into shiny paths of waxed tile floor. Immediately in front of me, inset deeply into the off-white wall, is a display case with various trophies, school awards and local memorabilia. A little higher up on the wall is a framed picture 
of the Monarch, Queen Elizabeth II, whose photo is flanked on one side by a large Canadian flag, and on the other side by the Red Ensign, the provincial flag with a red background, the Union Jack and the provincial coat of arms. I have only just entered the building but I already have a sense of the cultural economy of race within the school.]

School landscapes are bound with material forms of culture, prosaic connections which constitute recognizable elements of a cultural vocabulary traceable through western European history. This school, like most, is a landscape where Aboriginal ${ }^{1}$ students' lives are rarely given spatial expression. Here we draw attention to the ways in which school spatialities constitute and reinforce aspects of the social. This particular school is situated next to a First Nations reserve, has a significant population of First Nations students and yet is saturated in Euro-Canadian colonial frames of reference centered on the taken-for-granted notion of 'the nation'.

This paper explores the relationship and relevance of school landscapes to the question of race in Canadian schools. In particular, we investigate how the lives of Aboriginal students and staff are given spatial expression within school landscapes. A central tenet of this work is that schools, like any landscape, are landscapes of power (Lefebvre, 1991). Moreover, space is central to the construction of race and race is central to the unfolding of spatialities (Goldberg, 1993; Mohanram, 1999; Delaney, 2002; Peake and Kobayashi, 2002). Drawing upon in-depth case study research this paper utilizes a geographic focus to unpack the visual, spatial and ideological dimensions of schools as they are experienced in the everyday lives of Aboriginal students and staff. This paper has two purposes. It attempts to highlight the experiential aspects of racialized geographies within schools and, at the same time, it grapples with the processes that maintain or challenge the spatial conditions for the construction of whiteness.

Schools are the archetype of contact zones. Mary Louise Pratt (1992) coined the term 'contact zones' to refer to 'social spaces where disparate cultures meet, clash, and grapple with each other, often in highly asymmetrical relations of domination and subordination-like colonialism, slavery, or their aftermaths as they are lived out across the globe today' (p. 4, emphasis added). For those studying borderlands, transculturation, and various forms of hybridity in an emerging postcolonial world the concept of a contact zone has been a productive one. Increasingly, educational researchers are examining schools as contact zones-places where the values, ideologies and practices of cultures are brought together, often at the expense of the non-majoritarian culture (Halas, 1998; Brown, 2001; van Ingen and Halas, 2003).

This paper evolved out of a larger four-year research project that investigated the quality and cultural relevance of physical education for Aboriginal youth in Manitoba schools. ${ }^{2}$ Focus groups with over seventy high school and university Aboriginal students were followed by case study research at four schools and an action research project at two study sites. In order to analyze how race and racism affect the physical education and sport experiences of Aboriginal youth, we needed to understand the broader context of how our study participants experienced their daily school life. Aboriginal scholars and race theorists have outlined the ways in which Western models of education continue to be imposed on Aboriginal peoples throughout Canada. As a consequence there have been numerous calls by Aboriginal educators, leaders and communities for change in schools and curricula in order to create conditions where Aboriginal children and youth can become successful learners. Among the themes that have been identified in numerous reports and commissions on Aboriginal education are: the control and structure of public education; the under representation of Aboriginal teachers; the curriculum and its potential for reproducing social 
and cultural inequalities; and the overrepresentation of Aboriginal children in Special Education Categories (Mattson and Caffrey, 2001).

In general, our investigation received direction from Pratt's (1992) notion of the contact zone, Ladson-Billings' (1994) work on culturally relevant education and Catherine Ennis' (1999) conception of culturally relevant physical education. Our position going into the project was that there was much more at stake here than the 'add and stir' method of integrating Aboriginal perspectives and content into a physical education curriculum. As Celia Haig-Brown observes, it is not possible to 'collapse traditional Aboriginal education into being only formal knowledge' as this would 'miss the nuances and the complexity of what counts as education in traditional Aboriginal contexts' (2000, p. 2). Indeed, both a contact perspective and culturally relevant pedagogy refuse to be divorced from the context of structural inequalities and the difficulties of social difference as they are lived everyday by Aboriginal students. We are also influenced by critical race theory from which we took as a starting point that race and racism is deeply embedded in school landscapes and affects the education and lives of Aboriginal students (Delgado Bernal, 2002; Smith-Maddox and Solóranzo, 2002).

Education researcher Patti Lather (1991) claims that it is the job of the researcher to both get in and out of the way of the stories research participants tell us. As we interviewed Aboriginal youth and staff about their experiences at school and in physical education programs, we heard stories that shifted our thinking about cultural inclusion and belongingness. These other stories were all, in one way or another, landscape stories narrating the role of race and place-making in schools. Don Mitchell explains that landscapes are:

an ideological rendering of spatial relations. Landscapes transform the facts of place into a controlled representation, an imposition of order in which one (or perhaps a few) dominant ways of seeing are substituted for all ways of seeing and experiencing. (1996, p. 27)

As we listened to these landscape stories, we began to hear more about race and 'the phenomenology of belonging' (Delaney, 2002, p. 10). These racialized landscape narratives required that we more fully examine the ways in which race and space intersect and condition each other in schools.

Schools are landscapes shaped by colonial encounters, including the obvious legacy of Indian Residential schools where white superiority was violently asserted. Schools remain landscapes entangled with social power, cultural products and cultural meaning. Inherently the term 'contact zone' is spatial. It conjures up an image of a place, a location with fixed borders. What follows is an attempt to invigorate conversation about the inherent racialization of school landscapes. We begin with an excavation of four school landscapes focusing primarily on the cross-cultural schools to highlight race, Otherness, belonging, and cultural domination in schools. In particular we examine the ways in which race and racism inform, frame and map Aboriginal spaces of identity within schools.

In presenting our analysis, we need to first acknowledge the impact of socio-economic class on academic achievement. A large Manitoba study (Brownlee et al., 2004) clearly illustrates how differences in students' economic class backgrounds influence educational outcomes; by grade three, significant percentages of students from poor families lag behind their peers from middle and high income families on academic achievement scores. By high school, the success gap between students from different class backgrounds widens. Responsible educators must address the systemic challenges facing their students from low income families: they must design and deliver programs that not only engage 
young people who are struggling academically, but also provide the necessary resources and instruction so that students acquire the skills to graduate.

Thus, the intersection of class and race makes academic success particularly challenging for those Aboriginal youth who are living in families/communities that are locked into a marginalized economic base relative to their non-Aboriginal counterparts in Canada. We highlight this point to acknowledge Gosine's (2002) cautionary critique of how multicultural and anti-racism scholarship often essentializes racial identity construction in ways that fail to adequately consider the complexity, rupture and ambivalence that is masked by quests for identity. Finally, we are mindful that educational institutions are always works in progress: while the situational particularities of our data enable us to construct this critical analysis, we acknowledge that some of the issues we identify are currently being addressed by educators working daily to understand and improve the educational outcomes for Aboriginal students within their schools.

\section{Excavating School Landscapes}

Four schools in Manitoba, Canada are included in this study: two schools for Aboriginal students (one in an urban setting and one on a rural reserve) and two public cross-cultural schools (one urban and one in a rural setting). ${ }^{3}$ Characteristic of case study research, we relied on bricolage (Denzin and Lincoln, 1994), which incorporates a diverse set of research traditions and data collection activities, including interviews, participant observation, and collection of archival documents. During the case study phase of the project, our research team spent between two and five weeks at each school. Given that students' physical education experiences are embedded within the larger context of their overall school life, our fieldwork observations extended beyond the gymnasium to include observations of students before and after school, during class change, at lunch hour and in selected academic classes. Using an interpretive approach (Ellis, 1998), all field notes, transcripts and documents were analyzed through the construction of common and divergent themes relative to the research questions (Patton, 1990).

Schools are richly textured, power laden spatialities of everyday life. As we walked into each of the four schools we would consider the following guiding questions: "Whose school is it?' 'What images dominate this landscape'? 'How is the school "used" and by whom'? The answers to these questions exposed much about race and the politics of occupation in school landscapes. Specifically, these questions reveal who had a right to inhabit the dominant social, visual and intellectual spaces of the school.

\section{Cross-Cultural Schools}

Manitoba has a diverse Aboriginal population consisting primarily of Ojibway, Cree, Oji-Cree, Dakota, Dene and Metis ${ }^{4}$ (HRDC, 2002). Sixty-five percent of Aboriginal students in Manitoba attend cross-cultural schools, rather than Aboriginal or reservebased schools (Coalition for the Advancement of Aboriginal Studies, 2002). Most Aboriginal students are taught using provincial curricula with little, if any, infusion of Aboriginal epistemologies. Characteristic of the demographic make-up of the teaching population in Manitoba, a majority of the teaching staff at the cross-cultural schools were non-Aboriginal and white. As Kanu (2005) illustrates, the integration of Aboriginal cultural perspectives into the high school curriculum is mediated by non-Aboriginal teachers' general lack of pedagogical content knowledge, making it difficult for teachers to act as cultural brokers when translating the curriculum to Aboriginal students. 
Generally, cross-cultural schools offer limited Aboriginal cultural and language resources. For example, both cross-cultural schools in our study offered 'Aboriginal Awareness' or 'Native Studies' courses, which focus on the unique perspectives of Aboriginal peoples. At one school the Native Studies teacher was responsible for acting as a liaison and advocate for the Aboriginal students and a resource for other school staff interested in developing and adapting curriculum or programs to better meet the needs of Aboriginal students. With a student population over 1200 the Native Studies teacher was stretched thin, particularly as the Aboriginal population (estimated by school officials to be between 5 and $10 \%$ ) continued to grow each year.

At the urban school, the student body was comprised of diverse race, class and cultural backgrounds, with a mix of Asian, Black, White and Aboriginal students, including recent immigrants to Canada. The challenges of each school's cross-cultural dynamic was not immediately apparent, but came into clearer focus with increased time spent within each community. For example, despite the urban school's multi-cultural visage, there was more segregation than integration across diverse student groups. In the cafeteria, on the sports teams, walking the halls, and even in classes, it was the observation of teachers and students that different cultural groups 'stuck' together. A student teacher was puzzled by the apparent lack of integration which, as a member of a minority group, had not been his own schooling experience: even during his warm-ups in after school sport practices 'the White kids and the Filipino kids warm up together'. Talking to staff and students we were reminded of Ladson-Billings' (1994) earlier work which uncovered the realities of the urban schooling experience for African American students in what really were 'pseudo' integrated schools.

The lack of integration of students informed and complicated our understandings of 'multiculturalism' at the school. It also enabled us to theorize more clearly about 'contact zone' encounters. By mapping Aboriginal students' experiences of the various cultural spaces within this particular school, and how their spatial experiences are mediated by the social/educational practices of (the mostly) non-Aboriginal educators, we identify specific points of resistance, occupation and exclusion. As we show, many Aboriginal students in cross-cultural schools struggle to claim their own spaces within an educational system that fails to affirm their intellectual and cultural identities or expect their academic success.

\section{Excluded from the Centre: Interrogating the Presence of an Absence}

(Field notes): I'm looking for Amy, a young woman who I met during an Aboriginal Awareness class last Thursday. She was really keen to be involved in the research, but wasn't around yesterday and missed this morning's class. Perhaps she's since arrived, though Pat, the attendance monitor, hasn't seen her. I look for some of the other Aboriginal students, thinking they might know where Amy's at. To find them, I head to the Neechi doors, ${ }^{5}$ located at a corner of the school where Aboriginal students congregate for a smoke. Walking through the elaborate maze of corridors and stairways, past groups of classrooms organized by subject area or grade, students from a multitude of race and cultural backgrounds pass by. Two East Indian girls are laughing as one looks at the text message on her cell phone; a younger, Black youth with a back pack slung over his shoulder slips by a group of five chatty male and female Asian students. Ahead, I see Joe, a sponsored student from a Northern community who I interviewed last week. Wearing yesterday's clothes, he walks behind another group of students, on his own, as he does every day ... seamlessly blending into the busyness as he notches off another invisible lap of the school. A few decibels above the hustle and bustle, a crisp, male 
voice crackles over the PA system, announcing the day's roster of extra-curricular student activities: rehearsal for the school play, lunch hour intramural soccer, after school basketball practices, student council, yearbook, a meeting of the student unity group, details of a fund raising campaign for an upcoming school trip. It's a 'who's who' and 'what's what' of the school. As I listen and look around for hints of where I might find Amy, she's nowhere to be found.

\section{Claiming Intellectual Spaces: Why aren't Students in Class?}

The manner by which students travel through a school's hallways and corridors provide hints about identity and belonging; body language, dialogue, decibel levels, laughter, silence, collectivities and isolation are defining characteristics of social interaction. As discursive traits, they provide clues that help explain how inclusion/exclusion is manifest and experienced. To illustrate this point, we discuss how students moved into and out of the dominant cultural spaces within the school. We begin with the classroom, the intellectual centre of the school, and how Aboriginal student absenteeism impacted the teachers' social/educational practices.

With some exceptions (i.e., those Aboriginal students who were doing well in their classes), a significant number of students were not succeeding academically, particularly in relation to their non-Aboriginal peers. At one cross-cultural school, many Aboriginal students had dropped out between the time of the first focus group (spring) and the follow-up case study (fall and winter). Erratic attendance, arriving late for class, not changing for physical education class, not completing assignments, and getting into conflicts with teachers and/or other students were defining parameters of poor academic performance. While multiple factors contribute to absenteeism, the number of missing students reflected systemic patterns of academic failure. At 44\%, Manitoba has one of the lowest levels of school attendance for Aboriginal youth in all of Canada (HRDC, 2002). With less than one in two Aboriginal youth attending classes full time, keeping students in school and on task is a fundamental imperative for educators.

Theoretically, an academically-engaged student will regulate her or his performance in ways to ensure successful educational outcomes. Teachers will support an individual student's academic engagement by monitoring attendance, and provide assistance when a student returns after a missed class. At the urban school, the effectiveness of efforts to monitor the attendance of Aboriginal students was mixed. The physical size and architecture of the school, the large student population, the lack of information regarding each student's background, the context of where and with whom Aboriginal students were living within the community, along with the cultural disconnect between students and teachers, all influenced communications between the school and home. ${ }^{6}$

However, despite the obvious absenteeism of significant numbers of Aboriginal students, coupled with the challenges of providing inclusive educational experiences for a systemically marginalized and oppressed group, many teachers did not make an effort to track down those Aboriginal students who were missing from their classes. A number of teachers claimed to not know who their Aboriginal students were, while others did not see a need for a particular strategy because they believed their students did not want to be 'labeled' Aboriginal. Even with the presence of an attendance monitor, it was not uncommon for Aboriginal students to be absent for extended periods of time without the school having specific information about their whereabouts.

Crucially, a number of Aboriginal students commented that they liked it when teachers did not contact their home, stating that 'it's good that way'. In the following exchange, a 
young man reflects upon his attendance patterns since moving to a larger school. Although he clearly liked his new school where he felt safer and experienced less bullying than in his previous inner city neighborhood, he also like it that teachers did not hold him accountable for missing class:

Interviewer: (Regarding attendance) Do you come everyday?

Joseph: $\quad$ Yup, everyday. In the beginning of the year I came everyday but I'd never go to class when I first started. I'd be walking around, getting to know where the classes are.

Interviewer: Did anybody notice?

Joseph: $\quad$ Yeah . . . the teachers but they wouldn't say nothing. They'd just say, 'Hello' or 'how are you?' and I'd tell them 'I'm doing fine'.

Interviewer: Don't you think after three or four times, they should come and find out where you're at?

Joseph: $\quad$ They should, but they don't.

According to William, one of the Aboriginal educators, there was a tendency for some teachers 'to not want to call home' to check up on the Aboriginal students. He attributed this behavior to preconceptions about how involved Aboriginal parents would be in their children's schooling. 'They think, "aw, they won't care anyway ... they're not going to care about what this kid's doing so we'll just kinda' stay away from that. We'll let them not show up"'. Underlying assumptions such as these were communicated by a number of White teachers who viewed their Aboriginal students as having 'social problems' such as alcoholism and families where education was not valued as much as in non-Aboriginal families. Low expectations for parental involvement are lingering, leftover effects of Canada's colonial history; in this case, negative racial stereotypes pre-empt effective communication between non-Aboriginal teachers and the parents/guardians of absent students. These constraining beliefs need to be challenged, William cautions, by continually reminding oneself that '. ... every parent cares what their kids are doing'.

Nathan, a non-Aboriginal teacher who sought us out during the research, suggested that student engagement was less a function of colonial history than the system of 'red tape' that constrained a teacher's efforts to contact the home. The significant number of sponsored students, many of whom travel hundreds of kilometers back and forth to their home communities throughout the school term, also affected students' attendance patterns and performance in the class:

Nathan: Cause you're gonna have Aboriginal students who function well and ones that don't and for the ones that don't, there always tend to be these issues. Like they're coming off the reserves, they're living in (town) with an aunt or uncle, not their parents, there's a whole pile of variations on that. Other things include being sponsored, where often times, teachers don't know which students are sponsored. If there are attendance issues, then we talk with the aunt or uncle or whatever the case may be, we send them letters or make our phone calls. But it seems we should be talking more to the sponsoring agency perhaps. You know, it's done through the school, where there's people who watch that ... like (the attendance monitor) ... by the time it gets to that route, for the attendance monitor to do it, it's too late.

By too late, Nathan was speaking of students who are in 'regular' academic classes within the school's semester system where course content is completed over a term of five months. Without clear, identified strategies of support for students who frequently miss classes and fall behind in their course work, ${ }^{7}$ many Aboriginal students find themselves 
in a disadvantaged position. Furthermore, the fact they have fallen behind is visible to other students, who often do not have a contemporary and/or historical perspective to contextualize and inform their understandings of why some 'Aboriginal students' may need remedial assistance. Given individual cases of Aboriginal student success (i.e., the presence of Aboriginal students in class who are doing well), the notion that academic performance is a function of personal ability and motivation, as opposed to more systemic opportunities and constraints, dominates. ${ }^{8}$

Theresa, an Aboriginal educators charged with the responsibility for supporting students within the school, found herself feeling overwhelmed by the complexity of issues facing students. Similar to Nathan's concerns that interventions happened 'too late', Theresa believed that many students did not 'know how' to reach out and access help, thus leaving them feeling overwhelmed and academically inadequate:

Theresa: They have all the social issues going on. By the time I see them, they just feel inadequate and they feel overwhelmed by school work and they let it overwhelm them because they haven't reached out for help before they get kicked out [of school]. ... So they're not being acknowledged in any way for the situation that they're in, and they are blamed ... they feel that they're blamed.

Further compounding efforts to find solutions, Theresa pointed to the disconnect between how teachers and students perceived and interpreted the issues affecting the performance of students Often, students felt as though their lived experiences were being 'negated'.

Situated within a broader societal context of deeply embedded racism and negative stereotyping of Aboriginal peoples, combined with a pronounced ethnocentrism of the majority culture (Ponting, 1998), the more we listened to the divergent perceptions of our Aboriginal and non-Aboriginal study participants, the more we began to see the cultural dis-connect that impacted the quality of relationships between the two groups. One of the Aboriginal staff commented on the complexities of this cultural divide with the following observation:

It's not only the school ... it's the whole of society. Walking into a shopping center is the same as walking into the school. You can't say, 'Oh, the school is this way'. All of society is this way for Aboriginal people. They (Aboriginal students) come in and the administrators and teachers will say hello and that they want the students to do well. But they don't know how to establish a relationship with the Aboriginal students because their worlds are so completely different. I don't think that the teachers realize how completely different [their worlds are]. It doesn't have to be like that ... it's all in awareness and it's in respect.

The problematic nature of the cross-cultural teacher-student relationship was a recurrent theme in a number of conversations with students who were failing in school. Certainly, we interviewed Aboriginal youth who had favorite teachers and who felt they were respected in the school; however, for the many students who were struggling, their stories often centered on how (dis)respected they felt in the school. In an interview with a male student who had temporarily dropped out of school to look after family members who were ill, we asked if the presence of more Aboriginal teaching staff would make a difference:

Andy: Oh, heck yeah. That'd be a big difference. Because more students will feel more comfortable. The average teachers are like white and stuff, you know, a lot of white teachers. There's not a lot of Aboriginal teachers teaching in the city. We 
should have a lot more Aboriginal teachers because students will feel more comfortable around them.

... The white teachers, they don't care about you man, they just kick you out or whatever. 'I don't care what happens at home or why you were away'. If we get kicked out of class for something, they don't care. They show no remorse for people. They've been teaching for so long they think they know everything.

And so, there were tensions between how students and their teachers interacted. Students had difficulty seeking help, and their teachers did not always acknowledge or appreciate the complexity of the issues students' faced. Often, concerned educators were unable to provide timely support to those who were in need. Feeling behind or out of place, these Aboriginal students sit side by side with non-Aboriginal peers who have different (and often more supportive) student-teacher relationships. Nathan summed up his observations of how some Aboriginal students fall behind, saying:

... they'll come, they'll come late, they'll miss a couple of days here, miss a couple of days there ... then the issue is, you just can't catch up. Because when they do show up, you've already missed two days ... it's a snowball effect. If they try to do the next unit, OK, we do the next unit, start over again, the same thing. I think what ends up happening is that they [the students] become very frustrated.

Whether by ineffective reporting mechanisms, over-burdened class sizes, inadequate education resources for students who are academically behind, problematic teacherstudent relationships, or purposeful choice to not follow-up on student absences, each of these factors contribute to fewer Aboriginal students actively participating in the seminal academic/intellectual space within the school: the classroom. These isolating experiences of the school adds some insight to a question posed by Louise Champagne (2002) who asked: how is it that Aboriginal students continue to exit schools with entrenched feelings of inferiority and a lack of confidence in their own intelligence? The persistent, rampant absenteeism of an identifiable group needs to be addressed with adequate response. As an example, one school did respond to academically at-risk students by creating an alternative program (discussed in the following section). Without educational strategies that enable Aboriginal youth to experience real academic achievement, students remain excluded from the dominant cultural space of the school.

\section{Claiming the Margins: Smokers, 'Bad Kids' and Bandanas}

The segregation of racial groups within the school was particularly evident by where marginalized students chose to hang out during breaks. Teachers, practicing teachers and students could clearly identify these areas. Betty, an adolescent parent who had returned to the school after having her baby, described the geography of the school in these terms:

Betty: There's smoking corners at different parts of the school. The side where I go is on the [east] side. There's about three smoking areas ... and on the [east] side it's just Aboriginal. If there is someone white they are gonna' be an Aboriginal student's friend ... not strangers. The only time they would go there is if they're a friend of somebody. That's what you'll notice right away. If I go to the Aboriginal side, it's all Aboriginal.

Of note, the Aboriginal smokers' doors, known by Aboriginal students as the 'Neechi' doors (Neechi is a Cree word for friendship), were located next to where the alternative 
program for academically at-risk students was offered. With smaller teacher-student ratios, more flexible delivery of the curriculum (which had a strong experiential component), and supportive teachers (including an Aboriginal educational assistant who had an excellent rapport with students), the program effectively engaged many students who otherwise may have dropped out or been excluded from school. Fieldwork observations and interviews with students and staff involved in this program suggested that the alternative program provided a space where Aboriginal students did feel welcome and affirmed by their teachers. A complicating feature of this positive dynamic was the location of the program so close to the 'smokers' doors, which had its own stigma within the school. Within educational institutions, the regulation of smoking often contributes to the identification of smokers as 'bad' or unhealthy people. Thus, the concentration of groups of Aboriginal students (and, as Betty said, 'their friends') near the Neechi doors reinforced and essentialized notions of a collective, marginalized Aboriginal youth identity: if you want to find an Aboriginal student, check out the Neechi doors.

However, the 'smoking doors' was also a collective space where Aboriginal students exercised agency. In the following focus group excerpt, three grade nine girls provided a socio-historical analysis of how Aboriginal students took over occupation of the area now known as the Neechi doors. Speaking about a pervasive segregation of racial groups within the school, the girls expressed the opinion that other racial groups were more open to integration than the Aboriginal students, and, they were also afraid of the Aboriginal students:

Interviewer: So the other smoking areas are more [racially] mixed? And here it's just Native kids?

Student: $\quad$ Yeah ... [if Aboriginal students are at doors other than the Neechi doors] they tell us, 'You don't belong here. You can go back to your (Native) doors'.

Student: $\quad$ Once all the Natives started chilling there, it became the Neechi doors. And now, people are scared to go to the Neechi doors 'cause they're scared to get jacked.

Student: They think that if they walk through there they're gonna' get jumped ...

Interviewer: 'Cause the Native kids hang out there?

Student: $\quad$ Yeah, maybe five [non-Aboriginal] people pass through there in a day and they'll be going (fast).

While the characterization of Aboriginal students as dangerous to others contrasted with the 'shy', 'quiet' descriptors used by many teachers when speaking of their Aboriginal students, the image of the 'dangerous Aboriginal youth' resonates with deeply held stereotypes in Canadian society. In support of what the young women said, the identification of groups of Aboriginal students as 'bad' was a persistent dynamic within the school. On one field visit, the notable presence of two White teachers, arms folded, backs to their classroom doors, quietly speaking as they jointly surveyed the actions of two male Aboriginal youth who had stopped for a drink at the water fountain summed up a recurrent image of cross-cultural interactions based on surveillance and policing. The three young women who spoke in a celebratory tone that suggested they purposefully embraced their identities as 'bad' students; in the absence of respect through achievement, they sought respect through fear.

After a series of conflicts within the school, the grade nine girls claimed that they were no longer allowed to walk together in groups of larger than four, cause 'they think that if we're in a big group than we're gonna' go start shit with people or we're looking for a 
fight'. They energetically affirmed the notion that the other kids were 'scared of the Natives' even though they walk in a 'big pack'.

Student: $\quad$ (speaking about inter-racial relations) 'They're not scared of us when it's a group of three girls. But when it's a group of five guys and six girls, then they're scared and they'll just walk away. Like they get out of all of our ways when we're walking in the hall and they'll just move'.

Interviewer: How does that make you feel?

Student: $\quad$ Good (all laugh).

Student: $\quad$ It's like ... when it was just a little bit of us last year, we used to rule the school man, we did.

Student: $\quad$ Mandy ... (reference to another student outside their group)

Student: $\quad$ Yeah, everybody was pretty scared of her.

This group of female students also made mention of the uneven application of rules, which they believed unfairly targeted Aboriginal youth. Given the prevalence of criminal gang activity in the larger urban centre, the provincial government mandated schools to enforce an anti-gang dress code. Clothing that was perceived to be associated with criminal gangs was banned (for a brief critique of how this ban differentially affects students based on race and class, see Halas, in press). Although there was virtually no known criminal gang activity at the urban school, bandanas were banned. As the attendance monitor explained, some students viewed bandanas as cultural dress, and felt unfairly targeted by the rule. These students would say, 'Well, okay, the East Indian kids are wearing something on their heads so this is part of our heritage, why cannot we wear the bandanas?' Reinforcing this notion, a student complained that the teachers 'don't allow the Indians to wear bandanas' cause they think it's automatically associated with gangs. But then you see a White girl running around the school, the teachers say nothing about their bandanas'. These perceptions reinforced feelings of exclusion and complicated notions of what it was like to belong at the school.

\section{Claiming Cultural Space: Aboriginal Teachers and Staff Negotiate the Contact Zone}

Professional development opportunities to help teachers develop and implement culturally appropriate programming for Aboriginal students received a mixed response. At the urban school, volunteer school-based in-service sessions were not well attended, and in some cases, teachers were openly resistant to the notion of adapting their programs to the needs of Aboriginal students, leaving an enormous gap for the Aboriginal educators to fill.

Moreover, many teachers were not even aware of the programming and supports available for helping Aboriginal students acquire positive self and cultural identification. Even in the face of irrefutable statistics that describe Aboriginal student's disproportionate failure in school, several white teachers we encountered in this study where resistant to the very notion of explicitly placing attention on Aboriginal students as they felt it was best to maintain a 'color-blind' approach to teaching. Critical race theorists argue that teachers are often uncomfortable acknowledging students' racial differences and that this colorblindness masks a dysconscious racism, 'an uncritical habit of mind that justifies inequity and exploitation by accepting the existing order of things as given' (King in Smith-Maddox and Solóranzo, 2002, p. 67).

In the following excerpt Mary, one of the Aboriginal staff members, laments the school administration's resistance to establishing tangible and powerful representations of Aboriginal culture. Mary had purchased a teepee to help foster a sense of belonging for 
Aboriginal students. Moreover, the teepee held pedagogical usefulness as a vehicle of cultural remembering for all students.

Mary: We got to talking about a teepee I had purchased to create a visible representation of Aboriginal people in the school. Well because I was leaving [the school], there was talk of sending the teepee back since I was not going to be around any more. I was so ticked off with that ... I can't believe they were saying thisbecause I was leaving they are going to do away with it? They are not even looking at the reasons why it is here. ...To me they just missed the whole mark of it. I guess they didn't listen to why we had purchased the teepee in the beginning.

Mary's frustrations with the suggestion that the teepee could be removed from the school after she was no longer employed points to work that needs to done with educators to develop a respect and curiosity for the histories, cultures, and contemporary lifestyles of Aboriginal peoples.

Another Aboriginal teacher made the following observation about the lack of awareness of the Native studies program that was available in the school:

Who are they trying to make aware? When I was interviewed [for the job] they said the program is for everyone. I thought I'd see a lot of different groups in here, not just Native students. I thought this was supposed to be for the whole school. It's all Native kids here ... this is just like a holding pen. Sorry to put it that way, but it is just a holding pen for the Aboriginal students.

Rather than re-segregating Aboriginal students into an Aboriginal culture class, real integration of Aboriginal culture across a curriculum that is made available to all students could interrupt the defining Eurocentrism of schools (e.g., where are the teachers who study teepee design in geometry class?). There remains an obvious fissure between the availability of school resources and the integration of Aboriginal perspectives and content in the classroom, library and in the artifactual mediation of physical space within the school.

In the following excerpt, Theresa, an Aboriginal staff member discussed negotiations of cultural meaning that take place in school. Specifically, she reveals the ways in which the social space of the school impacts a sense of belonging and/or displacement for Aboriginal students:

Theresa: It is important for Aboriginal students, and all students for that matter, to see themselves reflected in the fabric of the school when they walk into a building in as many ways as possible. So it might be in staff, it might be in artifacts, and it might be in the processes and programs that we use in schools. There are a myriad of ways ... it cannot just be through a Native Awareness course.

A school division administrator responsible for over-seeing the delivery of services for the Aboriginal community acknowledged the importance of this dynamic, stating that: 'Kids need to see themselves in the school when they get there and these kids don't see themselves there in a lot of ways'.

School landscapes feel alien to most Aboriginal people (Silver et al., 2002). The solution to this overwhelming problem cannot be solved through an Orientalist fantasy (Said, 1978), where the projection of racialized iconography or specialized Aboriginal courses simultaneously secures white political and cultural domination. The mere presence of artifactual materials or Native Studies classes targeting Aboriginal students will not challenge the very foundations of racist practice. But as Theresa acknowledges, it is imperative to bring to light, more directly, the ways in which current school 
landscapes are complicit with historical racial formations and to stimulate imaginations toward refashioning school landscapes, design, teaching practices, and institutional structures. Therefore an understanding of race and space ought to be incorporated into school based research. To overlook the forms of subjection that racialize the Aboriginal body is to perpetuate the silence and Otherness of those upon whom colonial school landscapes are imposed.

A recent study conducted in Winnipeg, a city which boasts the largest concentration of urban Aboriginal people in Canada, concluded that schools are not reflecting or validating Aboriginal history or contemporary culture (Silver et al., 2002). The study's authors argue that 'if the educational system is not de-colonized, then we believe that Aboriginal people will continue to resist' (Silver et al., 2002, p. 37). This resistance takes many forms including 'behavioral problems', high rates of absenteeism, dropping out, an overall lack of interest and higher than average rates of failure. In physical education classes, many Aboriginal students' discomfort with the space of the 'change room' where they are required to undress and put on sport-appropriate clothing leads them to 'quit' programs where changing is mandatory (Champagne and Halas, 2003). A non-Aboriginal physical educator believed that teachers would make allowances for students if they knew that they were uncomfortable. But, he adds, in referring to some students who will not change, 'some kids, Aboriginal kids, are too shy or too proud to say it (tell us) '. 9 By placing the onus on the individual student to communicate feelings of discomfort (for being abnormal, by not having the right clothes, the right body, the right confidence to display oneself while changing), the underlying assumption is that $\mathrm{s} /$ he should take personal responsibility and confidently express their discomfort for not fitting into the 'norm'. Crucially, our research indicates that Aboriginal student resistance is solidly rooted in the fact that schools are places where they often feel like outsiders. As we have shown, one way to fit in and find their own spaces within the schools is to try to rule/claim the margins.

Just as the metaphor of a 'holding pen' was used to highlight the continued marginalization of Aboriginal pedagogy and students, the following excerpt speaks to the persistent erasure of Aboriginal students within the school landscape. Theresa, an Aboriginal educator, explains that confronting racism in the contact zone is difficult because in addition to the obvious and tangible forms of racism, such as the use of disparaging remarks, there are numerous ways in which race and racism operate that are less tangible, but which maintain the present social and structural arrangements of the school. She explains:

Theresa: Teachers need to become culturally competent. They need to understand the dynamics of what it is to live like an Aboriginal person in North America. This is our home country and we are made to feel like outsiders. That is the big picture and it comes through all the time in little issues. Students do not feel at home in this school. I have a hard time feeling at home in this school. It is all the intangible things like the atmosphere and the exclusion. It is really sterile here; it is not as tangible as someone making a disparaging remark. It is intangible.

It is difficult for our students to envision how well they can do, how well they could succeed in this society. The war against First Nations Peoples in North America wasn't only at the physical level, it was spiritual and intellectual, it shapes the whole way that people view the world. ... If students are learning about Canadian history and there is this very peripheral unit on Aboriginal perspectives what is that saying? It's saying that their history and contributions are not important. So where do they fit in?

Indeed, where do Aboriginal students 'fit' in school landscapes? ${ }^{10}$ As Stuart Hall reminds us 'identity is not already "there"; rather, it is a production, emergent, in process' (Yon 
2000, p. xi). White-controlled school landscapes are structured in ways that maintain, rather than challenge, racial hierarchies. African American scholar Beverly Tatum uses the term cultural racism to describe the 'cultural images and messages that affirm the superiority of Whites and the assumed inferiority of people of colour' (Silver et al., 2002, p. 40). David Delaney's (2002) comments are particularly helpful here for highlighting how whiteness is unmarked in the cultural economy of race within schools:

As part of the positive content of whiteness, transparency facilitates the invisibility of white privilege. Not the least important privilege is that white people usually have the option of thinking about race or not. The effects of privilege are rendered invisible, so whiteness takes on the appearance of normal (ordinary, unremarkable, neutral, fair, orderly, objective, and so on).... It also makes plausible the notion that racism consists in anomalous acts of discrimination. This then renders as natural, neutral, or innocent the spatialities through which whiteness - and white privilege-are maintained. (p. 11)

As noted in the preceding excerpts, racism can not be viewed as acts of individual prejudice that can be eliminated. Rather white privilege is written into the school landscape in ways that cover the often hidden subtext of race and racism.

The hidden subtext of racism can also be marked by the 'presence of an absence' (Rosenberg, 1997) where the figurative presence of race and racism is conveyed through the virtual absence of Aboriginal students in the celebratory spaces of the school. A vivid example is provided by the urban cross-cultural school's athletic program. Typically, the entrance to school gymnasiums are marked by 'walls of fame', where past and present sport achievements are visually commemorated with artifacts from each years' inter-school program. Behind protective glass lay team photos, award banners, medals and trophies representing generations of students who spent their school years as members of the athletic program. Sporting bodies, lined up side by side, convey notions of achievement and camaraderie. One day, a non-Aboriginal youth leader who runs an urban Aboriginal sport program visited the school. As he walked toward the gym, he paused to scan the pictures of student athletes in school uniforms. Looking up, down, and across he eventually turned his head back and pointedly asked: 'where are all the Aboriginal kids? Why aren't they on the teams?' It was through this research program that we have formulated a partial response to that question: they are not on the teams because, as a starting point, they are not in school.

In our discussion of cross-cultural schools, we focused on the ways in which race, and Whiteness in particular, underwrites the claiming of space within school landscapes. By studying the meanings that are 'written' into landscapes, as well as the ways in which people 'read' and experience the landscape (Knox and Marston, 1998), educators can better interrupt the ways in which school landscapes produce and reinforce racial difference. The social and the built environment represent particular identities, values and cultures. Similar to the ways in which specific discourses become authoritative and dominant, spatialities alert us to how certain histories and meanings are constructed, imposed and endure within landscapes. The relationship between race and power must be traced out in order to begin to consider what a more inclusive school landscape might look like.

Decolonizing school landscapes requires taking seriously the ways in which different cultures are located within asymmetrical power relations. For instance one might ask who has the power to decide how cultural practices, identities and histories will be presented and preserved within schools? What is needed to stem the tide of forgetting that obscures the lives of Aboriginal peoples within school geographies? The process of excavating school geographies requires that we face the uncomfortable realities of the colonial 
encounter itself. Over the past two decades, aided by the establishment of federal and public inquiries, there has been some acknowledgement of the abusive legacy of residential schooling. However, there is often little acknowledgement of the continued processes of racialization framing the experiences of Aboriginal students in cross-cultural schools. We now turn our attention to the contrasting landscapes of Aboriginal schools.

\section{Aboriginal Schools}

(Fieldnotes: The four colored sign outside the school reads: In-service December 8, Parent interviews December 18th, Pipe ceremony and feast December 21st).

All schools are beholden to a politics of racial representation. Aboriginal schools, like cross-cultural schools, are actively engaged in the cultural landscaping of identity. The reserve-based rural school included in our study is built to reflect and celebrate Cree culture. The school is designed with four wings or quadrants honoring the four directions and colors of humanity. Cree culture is not only reflected in the building design but throughout the social space of the school. Perhaps most evident is the reclamation of Cree language in the school, through classes, signage, and in the ceremonial practices undertaken each morning. In addition, pictures of Elders from the community are displayed on the walls of the school establishing the link between student learning and life in the community. In this instance, the Cree cultural value of honoring generational knowledge and wisdom is visibly woven into the school landscape; by contrast, traditional knowledge passed on by Elders to the young are typically ignored in Euro-Canadian schools. The collective identity expressed in the reserve school reflects local Cree culture and values.

Stuart Hall (1998) reminds us that typically racism operates through a binary system of representation which clearly marks, fixes and naturalizes the difference between belongingness and otherness. At both Aboriginal schools the naturalization of racism is challenged incisively resulting in a greater sense of belongingness for Aboriginal students. A non-Aboriginal teacher who has taught in both cross-cultural and Aboriginal schools observed that Aboriginal students demonstrate a greater sense of belonging at the reservation school:

Teacher: At a reserve school students are more open. They are free to talk, they're not afraid to come up with ideas and express them. I think that helps them. I have seen a lot of times in a cross-cultural school that some of the Aboriginal kids don't want to put their hands up, they don't want to participate because they are a minority, they feel kind of segregated.

School landscapes can not be separated from the knowledge and representations which express and repress particular identities (Yon, 2000). The two Aboriginal schools in our study offered a libratory, or at the very least a transformative, effect in that Aboriginal cultures were not seen through what Toni Morrison calls 'an economy of stereotypes' (Yon 2000, p. 18). For example, there are numerous texts at the reserve school which offer valuable insights to the history of the First Peoples and the land on which they live. The local Aboriginal Education Authority has developed textual and oral curriculum materials which outline seasonal practices, world views, values and beliefs as well as curriculum guides for school initiated courses on community history and Aboriginal issues. There are library resources that detail the forced settlements of different Aboriginal peoples and which highlight the ways in which the allocation of reserves initiated the current legacy of dependency. In addition, there are resources outlining acts of defiance such as the 1990 'Oka Crisis' which drew worldwide attention, catapulting Native land rights 
into the international spotlight. This is not to suggest that there are not tensions and issues of racism that operate within the school. Rather it is important to highlight a school landscape that in significant ways reinforces and affirms the lives of its students, presenting both strong identities and distinctions from majoritarian school landscapes.

Yet, there is a particular kind of dilemma that exists when attempting to gesture towards a school landscape attuned to difference. As researchers we are not advocating the practice of simply representing Aboriginal culture as a set of attributes or representations informed by Canadian ethnocentric policies of assimilation creating an imagined Aboriginal culture. We are equally aware of racial essentialisms and the paradox of 'fixing' notions of race. Rather we are arguing that it is necessary for educators to comprehend the ways in which Aboriginal student experiences within school landscapes are conditioned by their racialized treatment and, simultaneously to acknowledge how race necessarily conditions the social space of school landscapes.

At both Aboriginal schools, First Nations and Metis adults were visible as administrators, teachers, support staff and guidance counselors. Students appreciated this dynamic and often described very positive relationships with the adult educators. In one focus group during the first year of our study, a group of eight Aboriginal youth at the urban school made reference to how included they felt by referring to one of the female teachers with the words: 'That woman (downstairs) is all of our mothers'. Another student mentioned how much he tried hard to get along with his physical education teacher because he wanted to be a part of the sports teams which consisted of Aboriginals and 'you really wanted to make sure you were a part of that. Now if it wasn't Aboriginal, I don't think I would have tried to get along with my teachers'. The positive teacher-student dynamics influenced the overall culture of the school in meaningful ways: during fieldwork, a (White, male) substitute teacher revealed that he loved working at the school because the 'kids were so nice', a characterization that was opposite to much of what was described in our cross-cultural schools.

In addition to various library resources and curriculum materials from an Aboriginal perspective, there were pedagogical practices that held relevance and meaning to students' social and cultural realities. For example, the reserve-based school had its own registered trap line and an outdoor education program rooted in local ceremonies and traditional spiritual practices. An Elder from the community, along with a non-Aboriginal teacher, worked with the students in the outdoor and trapping programs introducing students to a broad range of skills to survive in the outdoors as well as traditional customs and skills used by the First Nations peoples to maintain a healthy and prosperous lifestyle with the land. Below the Elder involved with the trap line and outdoor program discusses the connection between the school program and the community:

Elder: In the north the moose is a well respected animal. Yesterday we were able to get a moose. A lot of kids haven't really been exposed ... On the way back the kids did a lot of reflecting. 'Oh, I didn't know that we were supposed to hang a bell up on a tree'. It is a sacred thing to honor the moose for allowing us to harvest it. They didn't know some of the cultural things after you have said a prayer. ... The kids talked about respect for the animal and talked about the lost generation because nowadays you don't see very many men praying. This is the generation-what we teach them might spread out. So it carries on the culture that they have been missing.

The urban Aboriginal school also utilized resident Traditional Advisors to foster an environment of respect and belonging within the school. Monthly pipe ceremonies were led by a traditional Elder and attended by all students and staff. Students also have the opportunity to participate in sweat lodge ceremonies and four seasonal feasts (spring, 
summer, fall and winter). The school also offers Aboriginal language, cultural and art programs that enable its students to increase self-identity through traditional cultural teachings. In addition to more culturally relevant school programming, most forms of iconography ${ }^{11}$ visible at both these schools work to supplant the master narratives of Euro-Canadian history and experience. The spatiality of inclusion at the urban Aboriginal school is evident in several ways including walls covered in both traditional and contemporary Aboriginal art, and a Medicine Wheel which is also used in teachings. The school offered numerous cultural activities like student drumming groups as a means to reaffirm cultural identity. School landscapes, such as these nurture a grassroots renewal of traditional values and encourage the continuity of Native epistemologies seamlessly brought to bear on secondary education.

With respect to deeply entrenched Eurocentric notions of what 'legitimate' schooling provides, the high quality of cultural programming offered at both schools can be viewed as secondary to the achievement of 'academic outcomes'. While attendance and school completion remained issues, both schools had specific intervention strategies to promote school engagement. At the rural school, student athletes needed to maintain regular school attendance in order to compete on interschool teams. When a new gym was built at the urban school, the principal attributed increased school engagement as a partial contributor (along with the strong cultural programs) to student attendance. When students compared their urban school to other public schools, they sometimes inferred a notion frequently communicated by non-Aboriginal educators, that all Aboriginal schools did not achieve 'real' educational outcomes for student success. A legacy of the disgraced residential schools, the simple fact that our young study participants were often encouraged to attend an all Aboriginal school by their 'aunties', 'cousins', 'friends' and other family members who said 'it was a good school' speaks to the act of reclaiming education. In this way, both Aboriginal schools provided examples of whiteness interrupted.

\section{Conclusion}

Since this study began, the urban school division has initiated a university-school division partnership that will increase the number of Aboriginal teachers in their schools. At the urban school, an Aboriginal transition program has been established to support sponsored students who are new to the school. Using an effective model of youth engagement, a nonAboriginal teacher has allied with students to create a more tangible, welcoming space for students. Concurrently, we continue to grapple with ways school geographies leave Aboriginal students feeling 'out of place'. While the contrasting landscapes of the all-Aboriginal versus cross-cultural schools identifies ways that Aboriginal students' cultural identities are affirmed in the Aboriginal-run schools, our point is not to advocate for the segregation of Aboriginal students from mainstream educational institutions. Rather, we call for a greater white race consciousness in understanding how school geographies are constructed. This article opened with a quote from George Henderson stating that interventions in landscapes are needed to bring about greater social justice. In schools such interventions would require what Mitchell calls 'deeply social-historical readings of the landscape, refusing to satisfy itself with surface readings of the landscape and delving into the gritty, often ugly, sometimes energizing, social history of specific places' (2003, p. 791). In other words, how might school landscapes be understood as a form of praxis to sustain an attentiveness to issues of racialization. In order to respond to and intervene in the school landscape educators need to hear the difficult stories of Aboriginal 
students and staff whose experiences within school landscapes are deeply embedded with 'whiteness'.

This paper was an attempt to invigorate geographical conversations about the racialization of school landscapes. No spatiality has escaped racialization (Peake and Kobayashi, 2002). Yet, most landscapes are made to appear as though ahistorical, devoid of any indications of social struggle around their production and maintenance (Lefebvre, 1991). Schools, like all landscapes, are the result of struggle, negotiation, and conflict. The goal of the article was to show how particular racial identities are constructed, represented and in turn experienced in school landscapes. It is well documented that a cultural/racial divide exists between Aboriginal students and the school system (Silver et al., 2002; Wilson and Wilson, 2002). Manitoba has the highest proportion of Aboriginal people of any other province in Canada. The province also has the lowest rate of school attendance among Aboriginal youth of any province or territory in Canada, and a high school graduation rate of $33.7 \%$ (HRDC, 2002). The teaching population at the secondary level in Manitoba is overwhelmingly homogeneous (mostly White and middle class). These teachers come into contact with an increasingly heterogeneous student population (students of color, including those from low-income backgrounds). In addition to few Aboriginal teachers and little Aboriginal content in the curriculum, Aboriginal educators report that cross-cultural schools do not adequately reflect their cultural values and daily realities.

In foregrounding the topic of racialized school landscapes as part and parcel of the Aboriginal students and staff's experience of belonging, we hope to expose the spatial processes which continue to secure white privilege within schools. Moreover, the responsibility to address the challenges faced by Aboriginal students cannot lie solely with Aboriginal staff members, liaison workers or teachers. By de-coding school landscapes the clearest ideological expressions of whiteness are unmasked and possibilities open up for creating new relationships between students by producing social relations and material landscapes that reflect the substance of Aboriginal students lives. In short, we seek to encourage the development of more equitable and race conscience school landscapes.

\section{Notes}

1. The 1982 Canadian Constitution Act recognizes three groups of Aboriginal people—Indians, Métis people and Inuit.

2. Our investigation received direction from the Maskwachees Declaration (2000) stating that: 'a sustainable commitment and investment in active living, physical activity, physical education, recreation and sport are essential to promote health and address social issues facing Aboriginal/Indigenous Peoples in communities across Canada'. Given the abject failure of the Canadian education system with regard to Aboriginal youth, and the potential of physical education to positively or negatively influence a student's overall experience of school, we documented Aboriginal youth's experiences in the gymnasium and school.

3. All identifying characteristics (e.g., names of participants and schools) have been removed from the data.

4. There are over 62 different First Nation communities in Manitoba. The diverse makeup of the Aboriginal population is not adequately captured in the term Aboriginal, Native or First Nations any more than the term Canadian captures the diverse cultural and ethnic variations of those who hold membership in this imagined community.

5. 'Neechi' is a Cree word for friendship. The Aboriginal students congregated at a what they called the Neechi doors, often to smoke, in the company of other Aboriginal students.

6. Given that the school division had many sponsored students (i.e., students who have moved from a rural or remote community to an urban centre to continue their high schooling), the school had an attendance monitor who acted as a liaison between the school and the students' sponsoring agency. In order to register the student, the sponsoring agency pays a set amount in student fees to the school division. The students are typically billeted with siblings, aunts or uncles, community members, or in some cases, were living on their own. 
7. For example, in 'sport schools', high school athletes who miss school due to out-of-province competitions are provided a laptop that allows the student to complete pre-arranged assignments and communicate with teachers via email. The student returns to school in a position to resume regular coursework in her or his classes.

8. In a series of teacher workshops that presented the findings from this study, many educators communicated a deep attachment to notions of meritocracy. Efforts to contextualize Aboriginal student achievement within social and historical perspectives were strongly resisted by a significant number of teachers.

9. While physical educators at our study school adapted their changing policy to better accommodate all students who were not feeling comfortable about changing, many other physical education teachers have been highly resistant to the notion of adapting their physical education policies. We have presented the study results to dozens of teachers who continue to police their students' participation by enacting policies of 'no changing, no participation'. Students who do not have the confidence to conform with the policy, or to challenge their teachers, drop out of physical education.

10. In a year one focus group interview on a university campus, a female student of Metis heritage told of her experience in a social studies class where a student teacher was delivering content about Aboriginal culture. When a group of non-Aboriginal students made disparaging comments about Aboriginal peoples (being drunks), their behavior was not interrupted. She was very upset, and attributed the lack of response by her teacher to the perception that there were not any Aboriginal students in the class.

11. Iconography is defined here as visual images that disclose symbolic meanings used to help bind a group of people together within and to a territory (Leib et al., 2001).

\section{References}

Anderson, K. (2002) The racialization of difference: Enlarging the story field, The Professional Geographer, 54(1), 25-30.

Brown, S.G. (2001) The bush teacher as cultural thief: The politics of pedagogy in the land of the indigene, The Review of Education/Pedagogy/Cultural Studies, 20(2), 121-139.

Brownlee, M., Roos, N., Fransoo, R., Guevremont, A., MacWilliam, L., Derksen, S., Kid, N., Bogdanovic, B. and Sirski, M. (2004) How do Educational Outcomes Vary with Socioeconomic Status? Key Findings from the Manitoba Child Health Atlas 2004, Winnipeg: Manitoba Centre for Health Policy.

Coalition for the Advancement of Aboriginal Studies (2002) Learning About Walking in Beauty: Placing Aboriginal Perspectives in Canadian Classrooms, Toronto: Canadian Race Relations Foundation.

Cosgrove, D. (1989) Geography is everywhere; culture and symbolism in human landscapes, in D. Gregory and R. Walford (eds) Horizons in Human Geography, Totowa, NJ: Barnes and Noble Books, 118-135.

Delaney, D. (2002) The space that race makes, The Professional Geographer, 54(1), 6-14.

Delgado Bernal, D. (2002) Critical race theory, Latino critical theory, and critical raced-gendered epistemologies: Recognizing students of color as holders and creators of knowledge, Qualitative Inquiry, 8(1), 105-126.

Ennis, C. (1999) Creating a culturally relevant curriculum for disengaged girls, Sport, Education and Society, 4(1), 31-49.

Goddard, T. (2002) Ethnoculturally relevant programming in northern schools, Canadian Journal of Native Education, 26(2), 124-133.

Goldberg, D.T. (1993) Racist Culture, Cambridge: Blackwell.

Haig-Brown, C. (2000) Some thoughts on protocol in university/community partnerships. NALL Working Paper, Paper presented at the Social Sciences and Humanities Research Council of Canada: New Approaches to Life Long Learning, OISE, University of Toronto.

Halas, J. (1998) 'Runners in the gym': Tales of resistance and conversion at an adolescent treatment center school, Canadian Native Education Journal, 22(2), 210-222.

Human Resources Development Canada (2002) Aboriginal People in Manitoba, Winnipeg.

Knox, P. and Marston, S. (1998) Places and Regions in Global Context: Human Geography. Upper Saddle River, NJ: Prentice-Hall.

Ladson-Billings, G. (1994) The Dreamkeepers: Successful Teachers of African American Children. San Francisco, CA: Jossey-Bass Publishers.

Lather, P. (1991) Getting Smart: Feminist Research and Pedagogy with/in the Postmodern, New York: Routledge.

Lefebvre, H. (1991) The Production of Space, Translated by D. Nicholson-Smith, 2nd edition, Malden, MA: Blackwell Publishers.

Leib, J., Webster, G. and Webster, R. (2001) Rebel with a cause? Iconography and public memory in the Southern United States, International Journal on Human Geography and Environmental Sciences, 52(4), 303-310.

Marshall, D. (2004) Making sense of remembrance, Social and Cultural Geography, 5(1), 37-54. 
Mattson, L. and Caffrey, L. (2001) Barriers to Equal Education for Aboriginal Learners: A Review of the Literature, Vancouver: British Columbia Human Rights Commission.

Mitchell, D. (2000) Cultural Geography, Malden, MA: Blackwell Publishers Ltd.

Mitchell, D. (2002) Cultural landscapes: the dialectical landscape-recent landscape research in human geography, Progress in Human Geography, 26(3), 381-389.

Mitchell, D. (2003) Cultural landscapes: just landscapes or landscapes of justice? Progress in Human Geography, 27(6), 787-796.

Monranram, R. (1999) Black Body: Women, Colonialism and Space, Minneapolis, MN: Minnesota Press.

Nash, C. (2003) Cultural geography: anti-racist geographies, Progress in Human Geography, 27(5), 637-648.

Peake, L. and Kobayashi, A. (2002) Policies and practices for an antiracist geography at the millennium, The Professional Geographer, 54(1), 50-61.

Ponting, J. (1998) Racism and stereotyping of First Nations, in Vic Satzcwich (ed.) Racism and Social Inequality in Canada. Concepts, Controversies and Strategies of Resistance, Toronto: Thompson Educational Publishing, Inc., 269-298.

Pratt, M.L. (1992) Imperial Eyes: Travel writing and transculturation, New York: Routledge.

Rosenberg, P. (1997). Underground discourses: Exploring whiteness in teacher education, in M. Fine, L. Weis, L.C. Powell and L. Mun Womg (eds) Off white. Readings on Race, Power and Society, New York: Routledge, 79-89.

Said, E. (1994) Culture and Imperialism, New York: Vintage Books.

Schein, R.H. (2002) Race, racism, and geography, The Professional Geographer, 54(1), 1-5.

Silver, J., Mallett, K., Greene, H. and Simard, F. (2002) Aboriginal education in Winnipeg Inner City Schools, Winnipeg: Canadian Centre for Policy Alternatives-Manitoba.

Smith-Maddox, R. and Solórzano, D. (2002) Using critical race theory, Paulo Freire's problem-posing method, and case study research to confront race and racism in education, Qualitative Inquiry, 8(1), 66-84.

Steinhauer, E. (2002) Thoughts on an indigenous research methodology, Canadian Journal of Native Education, $26(2), 69-81$.

van Ingen, C. and Halas, J. (2003) Sites of learning? The challenge of location, racism and quality physical education for Aboriginal youth in Manitoba schools. Paper presented at the North American Society for the Sociology of Sport, Montreal.

Wilson, S. and Wilson, P. (2002) First Nations education in mainstream systems, Canadian Journal of Native Education, 26(2), 67-68.

Yon, D.A. (2000) Elusive Culture, New York: State University of New York Press. 